\title{
Modeling of the kinematic geometry of spur gears using matlab
}

\author{
${ }^{1}$ Peter I. Anakhu , ${ }^{1}$ Abiodun A. Abioye, ${ }^{1}$ Christian A. Bolu and ${ }^{1}$ JosephAzeta. \\ ${ }^{1}$ Mechanical Engineering Department, Covenant University, Ota, Nigeria
}

\begin{abstract}
The analytical method of gear design is calculation-intensive and it is usually difficult to achieve optimum backlash and interference-free involute profile that are required to generate geometrical compatibility in a pair of meshing gears when design procedure is entirely based on this method. Some amount of backlash is often required in the assembly of gears but excess backlash can lead to increase vibration and wear of the gear assembly. Also, interference-risk profile can result in undercutting of gear tooth. This paper optimized a spur external involute-profile gear by developing an application for the modeling of its geometrical compatibility using Matlab ${ }^{\circledR}$. The application uses existing models to test for interference and a proposed model to determine effective backlash in a gear. The backlash values resulting from the application are more confined and the model is applicable to a wider range of modules suggested by American Gear Manufacturers Association. Simulation of the gear-set in Solidworks ${ }^{\circledR}$ for kinematic geometry presents an interference-free tooth contour and an effective backlash.
\end{abstract}

\section{Introduction}

A gear is a wheel on which toothed members are cut to transmit rotary motion or rotational force (torque) from one shaft to another $[1,2]$. Gears are generally the most rugged and durable machine elements for transmitting mechanical power $[3,4]$. In particular, involute gears are mission critical and indispensable elements in the design of motion and power transmission applications [5]. Such applications include external gear pump [6], wrist mechanism of a spherical parallel manipulator [7], automobile and aircraft power transmissions and more.

However, gear design is a very complicated process $[8$, 5]. The complexity is not unconnected with the combined basic design requirements imposed by the fundamental law of gearing, the kinematics of the gear tooth profile, the variable loading of gear tooth, the joint rolling and sliding contact between curved tooth surfaces, and the gear interaction with other machine elements [9]. The law states that a pair of meshing gears must transmit constant velocity ratio throughout the mesh [10]. That is, the ratio must not vary between when a given pair of teeth comes into mesh and when they go out of mesh [3]. Any such variation will produce oscillation in the output velocity and torque, even if the input is constant with time [10]. Therefore, a design objective to conform with the fundamental law of gearing and to obtain gear teeth that will run smoothly through the angle of action must consider three major design tasks, viz: (1) to avoid interference, (2) to achieve a contact ratio greater than one to assure of one tooth pair (preferably more) is in contact at all times and (3) to provide an optimum amount of backlash in the mesh [9]. Interference defines the contact of portions of tooth profiles, around the flanks, that are not conjugate [11]. Contact ratio is a method used to determine how many teeth are in contact at any time and the possibility of load sharing among the teeth [4]. Backlash is the clearance between the width of space and tooth thickness, both measured on the pitch circle, to compensate for unavoidable inaccuracies in gear assembly $[12,4]$.

Table 1. Nomenclature: Gear terms, symbols and description

\begin{tabular}{|llll|}
\hline Symbols & Description & Symbols & Description \\
$m$ & module & $k$ & $\begin{array}{l}\text { A factor by } \\
\text { which the } \\
\text { standard } \\
\text { addendum of } \\
\text { the gear } \\
\text { should be } \\
\text { multiplied. }\end{array}$ \\
& $\begin{array}{l}\text { Pressure } \\
\text { angle }\end{array}$ & $u$ & Gear ratio \\
$d_{p 1}$ & $\begin{array}{l}\text { Pitch circle } \\
\text { diameter of } \\
\text { pinion }\end{array}$ & $z_{P}$ & $\begin{array}{l}\text { Number of } \\
\text { teeth on } \\
\text { pinion }\end{array}$ \\
& $\begin{array}{l}\text { Pitch circle } \\
\text { diameter of } \\
\text { gear }\end{array}$ & $z_{G}$ & $\begin{array}{l}\text { Number of } \\
\text { teeth on gear }\end{array}$ \\
\hline
\end{tabular}




\begin{tabular}{|llll|}
\hline$\frac{d_{p a}}{2}$ & $\begin{array}{l}\text { Limiting } \\
\text { function of } \\
\text { interference }\end{array}$ & $R_{\text {actual }}$ & $\begin{array}{l}\text { Addendum } \\
\text { radius of the } \\
\text { gear }\end{array}$ \\
$j$ & Backlash & \\
\hline
\end{tabular}

To avoid violating the law of gearing, the gear tooth contours on mating teeth must be conjugates of one another $[12,10]$. The authors argue that one of the possibilities of tooth contours for conjugate pairs that is useful as gear teeth for practical application is the involute contour. Also, involute curve is the most widely used shape for creating the active profiles of spur and helical gears to achieve constant velocity throughout the mesh Figure $1[8,1]$. This study developed an application for the modeling of involute-profile gears in consideration of interference-free contour and optimum backlash using Matlab $^{\circledR}$ and Solidworks ${ }^{\circledR}$.

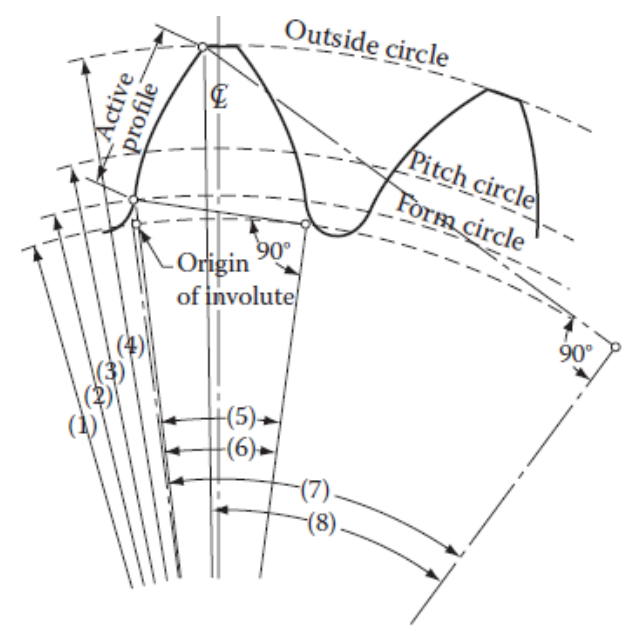

Figure 1. Active profile of an involute curve

\section{Review of past work}

In designing a mechanism, the real work lies in the determination of the sizes and shapes of its members [13]. Gear, as a type of mechanism, often requires complicated analysis to determine its optimum geometry [9]. Similarly, gear performance is in turn greatly dependent on gear tooth shape [14]. To this effect, the author suggests the optimization of gear tooth geometry as part of the design process to maximise gear drive performance. The tooth geometry optimization is aimed at increasing load capacity, revolution per minute (RPM), life span, and reducing vibrations and noise. The developed application will optimize the tooth shape of a spur gear using involute profile.

Several literatures have proposed different methods for interference-free design. They noted that in a gear design process, when interference is present, it is not a good practice to proceed on the design with the resulting parameters. It may lead to overlapping of the involute profiles of the gear or cut into the mating gear [15] thereby causing undesirable noise and early gear failure. One method involves producing gears through generation process that automatically eliminates interference by removing the interfering portion of the flank through the cutting tool [16]. However, the authors argue that this merely substitutes the original problem with another one called undercutting and it considerably weakens the gear. Undercutting is the removal of a portion from the active profile of the tooth by secondary cutting action [1]. Other methods, based on gear geometry, involve the use of minimum number of teeth on the pinion to check for interference. For a spur gear-set with a gear ratio of unity, the lowest number of teeth on both gears without interference may be determined from equation 1 [17].

$$
z_{P}=\frac{2 k}{3 \sin ^{2} \alpha}\left(1+\sqrt{1+3 \sin ^{2} \alpha}\right)
$$

When the gear-set is for a speed reduction application in which the gear ratio is more than unity, the lowest number of teeth on the pinion without interference is given in equation 2 [11]

$$
z_{P}=\frac{2 k}{(1+2 u) \sin ^{2} \alpha}\left(u+\sqrt{u^{2}+(1+2 u) \sin ^{2} \alpha}\right)
$$

These models are based on using more teeth on the pinion to obtain interference-free gear. However, if the pinion is to transmit a given amount of power, increasing the number of teeth on the pinion requires a simultaneous increase in the pitch diameter [16]. On the other hand, undercut-free design usually requires lower number of teeth [1]. Analytical approach to this trade-off may be intensive and error-prone. Therefore, an application for testing interference-free geometry is developed to reduce the drudgery. The application provides better flexibility in the optimization of interference-free gear tooth. It is based on a more general model of checking interference in involute gear geometry for most types of gears including spur, helical, bevel and more [15]. The objective function is to determine that the actual addendum radius is less than or equal to the maximum value of addendum radius of the gear to avoid interference. There is a maximum possible gear addendum that should avoid interference [3]. Therefore, the module can be reduced to design a gear geometry with interference-free contour based on the models below.

$$
R_{\text {actual }}=\frac{d_{p 2}}{2}+m
$$

$$
\frac{d_{p a}}{2}=\sqrt{\left(\frac{d_{p 2}}{2}\right)^{2} \cos ^{2} \alpha+\left(\frac{d_{p 2}}{2} \sin \alpha+\frac{d_{p 1}}{2} \sin \alpha\right)^{2}}
$$

$R_{\text {actual }} \leq \frac{d_{p a}}{2}$

In addition, using the right cutter number to generate a tooth profile is important in achieving interference-free geometry. Cutter number usually depends on the number of teeth on a gear [18]. The developed application will determine the cutter number based on the number of teeth on a gear.

The unavoidable inaccuracies in gear assembly has often impose the requirement of making the tooth thickness slightly thinner than the width of space between teeth, both measured on the pitch circle, to provide some clearance and this always result in backlash, Figure 2, [12, 
4]. Consequently, in many applications, gears exhibit various backlashes that occur because of the loose fit essentially required between two meshed gears. While generous backlash is suitable for power gearing, narrow backlash is preferred for control gearing [1]. Optimum backlash is very critical in gear assembly and in providing a clearance for the lubrication of mating gear pair. Thus, the amount of backlash for each application is often indicated for that particular application and discretion is often required in utilizing such values for design [8]. For instance, a table of backlash was suggested as a guide for gear design for spur, helical, bevel, and spiral bevel gears [8]. But the author equally cautioned against using it in every design application. As useful as backlash could be for gear assembly, extra backlash could lead to loss of motion and causes undesirable gear performance, especially for reversing gear drive [1]. It usually increases stress and wear of the mating gears and also causes undesirable positional error in some applications [13]. The proposed model used in developing the application will generate a tooth geometry that has a more effective backlash and may be used for any module.

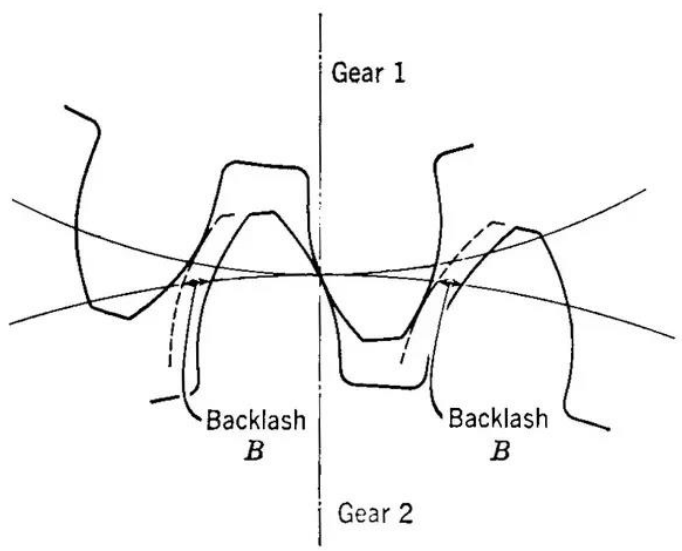

Figure 2. Backlash in gears

\section{Materials and methods}

\subsection{Design and Modeling Parameters}

The application adopted standard modules and pressure angles as published by American Gear Manufacturers Association (AGMA). The same module and pressure angle were used for both pinion and gear wheels because standardised cutting tools are available for such gear teeth geometry [5].

In determining an interference-free involute profile, a more general model is used in the application. The limiting functions for checking interference in a gear tooth contour are given in equations 3 to 5 and reproduced here as equations 6 to 8 .

$$
\begin{gathered}
R_{\text {actual }}=\frac{d_{p 2}}{2}+m \\
\frac{d_{p a}}{2}=\sqrt{\left(\frac{d_{p 2}}{2}\right)^{2} \cos ^{2} \alpha+\left(\frac{d_{p 2}}{2} \sin \alpha+\frac{d_{p 1}}{2} \sin \alpha\right)^{2}}
\end{gathered}
$$

$$
R_{\text {actual }} \leq \frac{d_{p a}}{2}
$$

Interference is avoided if the addendum radius of the gear is less than or equal to the square root of the sum of squares of the base radius and the product of centre distance and pressure angle. Decreasing the module and increasing the gear pitch diameter is usually sufficient to avoid interference.

Backlash optimization using the proposed model is based on the hypothesis that backlash is a function of pitch circle diameter, $d_{p}$, the inverse of the number of teeth, $z$, and pressure angle, $\alpha$. That is

$$
j=f\left(d_{p}, \frac{1}{z}, \frac{1}{\alpha}\right)
$$

\subsection{Simulation analysis}

The developed application was used to test a set of design variables including pressure angle, module, and number

\begin{tabular}{|c|c|c|c|}
\hline Pressure angle ( $)$ & 20 & & \\
\hline $\begin{array}{l}\text { Number of teeth } \\
\text { on pinion }\end{array}$ & 18 & & \\
\hline $\begin{array}{l}\text { Number of teeth } \\
\text { on gear }\end{array}$ & 24 & & \\
\hline Module & Interference & $\begin{array}{l}\text { Suggested } \\
\text { backlash* } \\
(\mathrm{mm})\end{array}$ & $\begin{array}{l}\text { Backlash } \\
\text { from } \\
\text { model } \\
(\mathrm{mm})\end{array}$ \\
\hline 25 & $\begin{array}{l}\text { Interference- } \\
\text { free }\end{array}$ & $0.63-1.02$ & 0.625 \\
\hline 20 & $\begin{array}{l}\text { Interference- } \\
\text { free }\end{array}$ & $\begin{array}{l}\text { matching } \\
\text { values }\end{array}$ & 0.500 \\
\hline 18 & $\begin{array}{l}\text { Interference- } \\
\text { free }\end{array}$ & $0.46-0.69$ & 0.450 \\
\hline 12 & $\begin{array}{l}\text { Interference- } \\
\text { free }\end{array}$ & $0.35-0.51$ & 0.300 \\
\hline 15 & $\begin{array}{l}\text { Interference- } \\
\text { free }\end{array}$ & $\begin{array}{l}\text { matching } \\
\text { values }\end{array}$ & 0.375 \\
\hline 10 & $\begin{array}{l}\text { Interference- } \\
\text { free }\end{array}$ & $0.28-0.41$ & 0.250 \\
\hline 8 & $\begin{array}{l}\text { Interference- } \\
\text { free }\end{array}$ & $\begin{array}{c}0.23-0.36 \\
\text { No }\end{array}$ & 0.200 \\
\hline 7 & $\begin{array}{l}\text { Interference- } \\
\text { free } \\
\text { Interference- }\end{array}$ & $\begin{array}{l}\text { matching } \\
\text { values }\end{array}$ & 0.175 \\
\hline 6 & $\begin{array}{l}\text { free } \\
\text { Interference- }\end{array}$ & $0.18-0.28$ & 0.150 \\
\hline 5 & $\begin{array}{l}\text { free } \\
\text { Interference- }\end{array}$ & $0.15-0.23$ & 0.125 \\
\hline 4 & $\begin{array}{l}\text { free } \\
\text { Interference- }\end{array}$ & $0.13-0.20$ & 0.100 \\
\hline 3 & free & $0.10-0.15$ & 0.075 \\
\hline
\end{tabular}
of teeth on pinion and gear wheels as shown in Table 2.

Table 2. Comparison of suggested backlash with modeled backlash 


\section{2}

Interference-

free $\quad 0.08-0.13 \quad 0.050$

Interference-

1

free

$0.05-0.10$

0.025

\section{*Source: Radzevick, 2012}

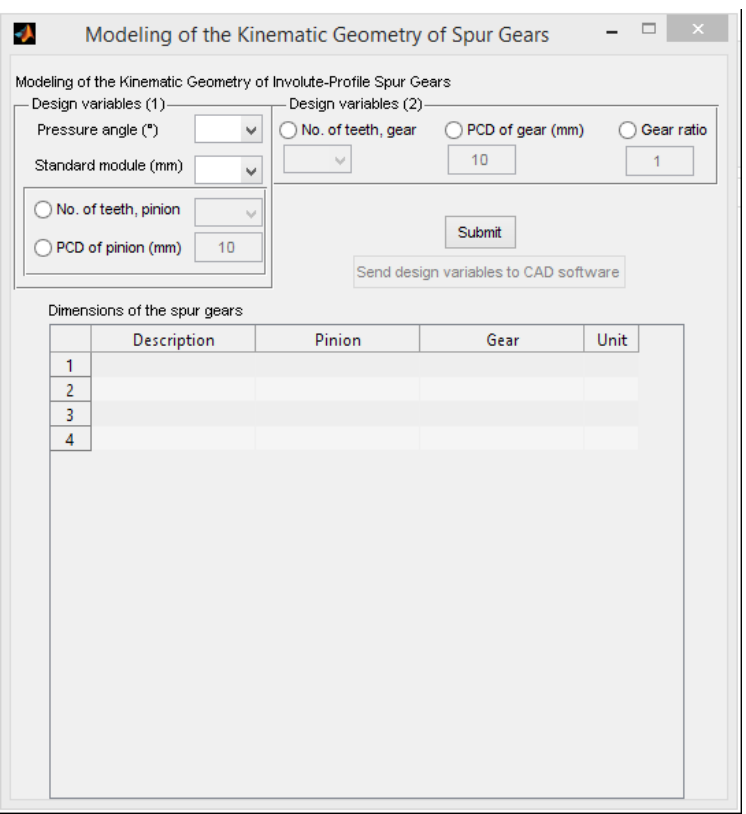

Figure 3. Spur gear geometry modeling GUI

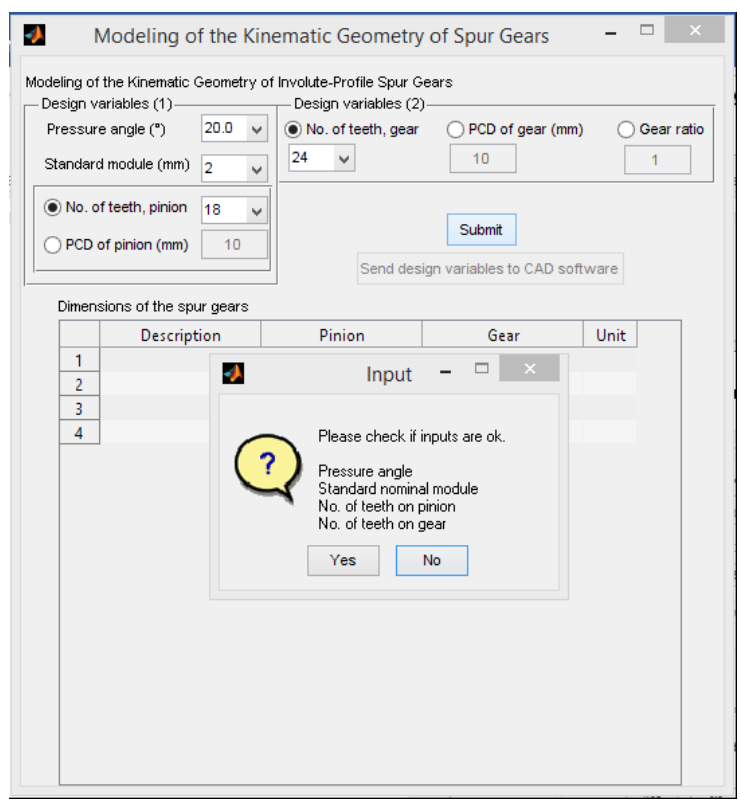

Figure 4. Modeling with gear design variables

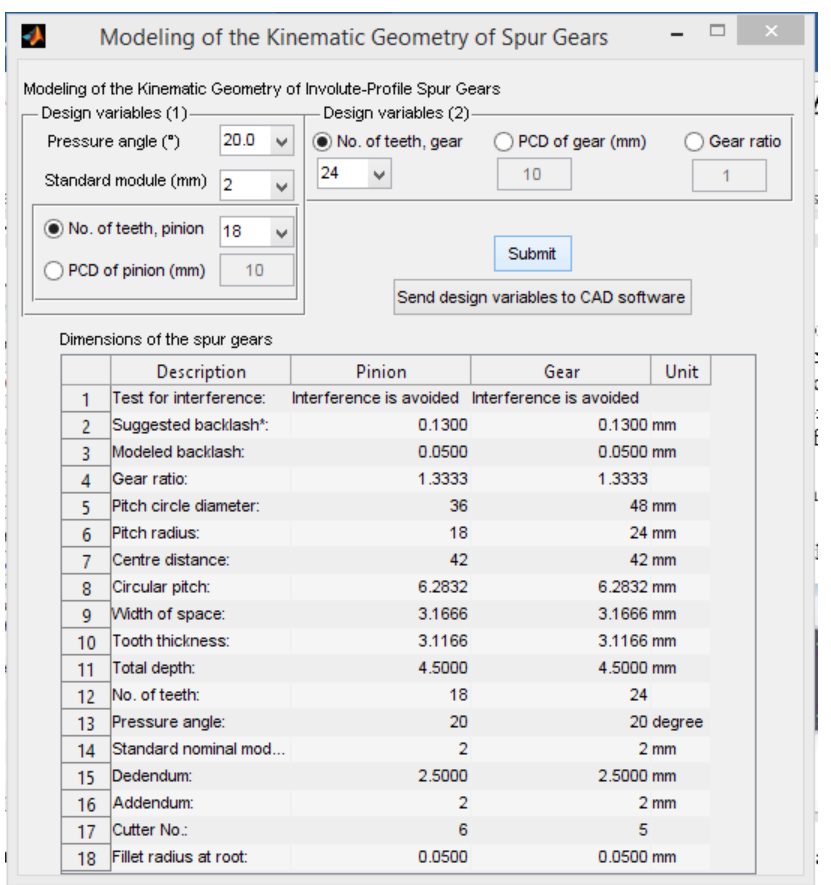

Figure 5. Modeling output

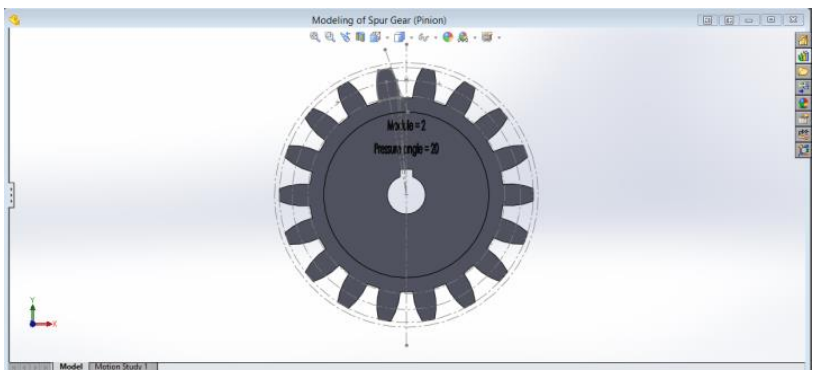

Figure 6. 3D Model of the pinion wheel

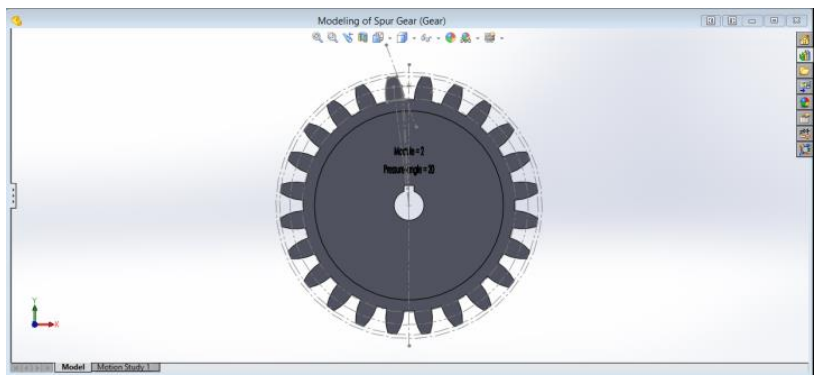

Figure 7. 3D Model of the gear wheel

\section{Results}

Backlash values suggested by previous authors are applicable to a narrow range of modules. Some authors limited the use of such values in certain design. The proposed model for this application can be used for a combination of any module, pressure angle and number of teeth to determine the optimum backlash required for the given design. Design of spur gear by modeling its kinematic geometry with this application created an involute-profile gear pair in Solidworks ${ }^{\circledR}$, Figure 8 . The application can generate text files for any parametric 
CAD software to create a 3D model of an involute-profile gear. The text file synchronises the computation and the 3D modeling of the gear in a CAD software. It also tests for interference-free or interference-risk portion on the involute profile. The backlash model for gear tooth design is dependent on the design variables such as pitch circle diameter, $d_{p}$, the inverse of the number of teeth, $z$, and pressure angle, $\alpha$. Therefore, it is simultaneously generated as shown in Table 3 rather than look-up tables.

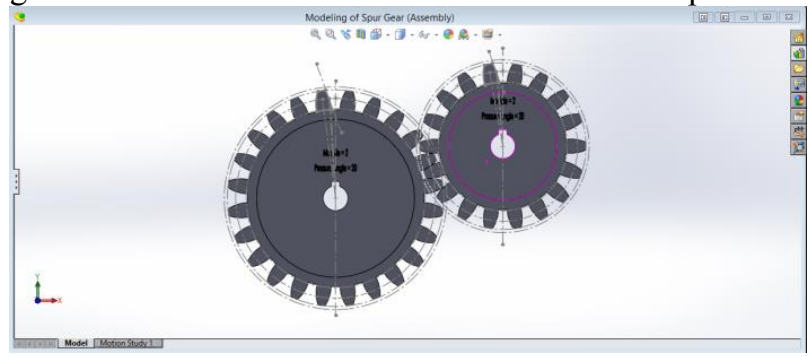

Figure 8. 3D Model of the gear assembly

\section{Conclusions}

In this study, the tooth shape of a spur gear was modeled using Matlab $^{\circledR}$ and Solidworks ${ }^{\circledR}$. The developed application was used to determine the effective backlash during the modeling of the gear tooth shape. Backlash can be obtained for any module and/or a combination of other gear design variables including pressure angle, number of teeth on pinion and gear, and gear ratio without the need for a look-up table or the use of thumb rule. Also, the presence of interference can be checked during the modeling process and the designer is prompted to adjust input variables to create an interference-free geometry. Furthermore, the application selects a cutter number depending on the number of teeth on a gear. Finally, in addition to the accuracy of the application, time of computation involved in gear tooth modeling is drastically reduced.

\section{References}

1 P.S. Radzevick, Dudley's Handbook of Practical Gear Design and Manufacture. 2nd Edn. CRC Press, Taylor \& Francis Group, London, (2012), ISBN 13: 978-1-4398-6602-3

2 R.N.C. Peter, Mechanical Design Engineering Handbook. Butterworth Heinemann, (2013), DOI: https://doi.org/10.1016/B978-0-08-097759-1.000083 . Available online www.sciencedirect.com/science/article

3 C.R. Juvinall and M.K. Marshek, Machine component design: 5th Edn. John Wiley \& Sons Singapore Pte. Ltd., (2012), ISBN 978-1-118-092262
4 C.A. Ugural, Mechanical Design of Machine Components. 2nd Edn. CRC Press, Taylor \& Francis Group, (2015), ISBN 13:978-1-4398-8780-6 (Hardback).

5 A. Amani, C. Spitas and V. Spitas, Generalised nondimensional multi-parametric involute spur gear design model considering manufacturability and geometrical compatibility. Mechanism and Machine Theory 109, 250 - 277, (2017). Available online www.elsevier.com/locate/mechmachtheory

6 X. Zhao and A. Vacca, Formulation and optimization of involute spur gear in external gear pump. Mechanism and Machine Theory 117, 114 - 132, (2017). Available online www.elsevier.com/locate/mechmachtheory

7 L-W. Tsai, Robot analysis: the mechanics of serial and parallel manipulators. John Wiley \& Sons, Inc., (1999), ISBN: 0-471-32593-7

8 W.D. Dudley, Handbook of Practical Gear Design. CRC Press LLC, (1994), www.crcpress.com ISBN: $1-56676-218-9$

9 A.J. Collins, R.H. Busby and H.G. Staab, Mechanical Design of Machine Elements and Machines. 2nd Edn. John Wiley \& Sons, USA, (2010), ISBN 13: 978-0470-41303-6

10 L.R. Norton, Machine Design: An Integrated Approach. 3rd Edn. Pearson Prentice Hall, (2006), ISBN: 0-13-202012-2

11 E.J. Shigley and R.C. Mischke, Mechanical Engineering Design. 6th Edn. McGraw-Hill Education (Asia), (2001), ISBN: 0-07-365939-8

12 J.B. Hamrock, R.S. Schmid and B. Jacobson, Fundamental of Machine Elements. 2nd Edn. (2005), ISBN 0-07-246532-8

13 R.L. Norton, Design of Machinery: An Introduction to the Synthesis and Analysis of Mechanisms and Machines. 2nd Edn. McGraw-Hill Inc, USA, (1999), ISBN 0-07-048395-7

14 A.L. Kapelevich, Direct Gear Design. CRC Press, Taylor \& Francis Group, (2013), ISBN 13: 978-14398-7618-3 http://www.taylorandfrancis.com

15 S.A. Hall, R.A. Holowenko and G.H. Laughlin, Theory and Problems of Machine Design. Tata McGraw-Hill Publishing company Ltd, (2002), ISBN 0-07-048333-7

16 R.G. Budynas and J.K. Nisbett, Shigley's Mechanical Engineering Design. McGraw-Hill Education (Asia), (2008), ISBN 978-007-125763-3

17 R. Lipp, "Avoiding Tooth Interference in Gears," Machine Design, Vol. 54, No. 1, pp. 122 - 124, (1982)

18 L. Ivan, Gears and gear cutting, Special Interest Model Books Ltd, England, (2003), ISBN 1-85242911-8 